\title{
Práticas Híbridas e Alquimia: considerações sobre a fotografia através dos processos fotográficos históricos
}

\section{Hybrid practices and Alchemy: considerations on photography through historical photographic processes}

Resumo: Este artigo propõe uma reflexão teórica a partir do meu processo de trabalho em Poéticas Visuais na área da fotografia. Procurou-se analisar os conceitos de práticas híbridas e alquimia a partir dos Processos Fotográficos Históricos.

Palavras-chave: Fotografia. Processos Fotográficos Históricos. Materiais fotossensíveis. Artes visuais. Alquimia.

Abstract: This article proposes a theoretical reflection from my own process and work in Visual Arts, in the area of photography. I have endeavored to analyze the Historical (Primitive or Alternative) Photographic Processes while hybrid and alchemic practices.

Keywords: Photography. Historical photographic processes. Photosensitive materials. Visual arts. Alchemy.
BRÄCHER, Andréa. Práticas Híbridas e Alquimia: considerações sobre a fotografia através dos processos fotográficos históricos. Informática na Educação: teoria \& prática, Porto Alegre, v. 11, n. 2 p. 47-52, jul./dez. 2008
Andréa Brächer

UNISINOS/ULBRA

\section{I nício do Percurso}

A pesquisa começa pelo meio, como escreve Jean Lancri. "É no meio que convém fazer a entrada em seu assunto. De onde partir? Do meio de uma prática, de uma vida, de um saber, de uma ignorância. Do meio desta ignorância que é bom buscar, no âmago do que se crê saber melhor."1

Minha prática em fotografia vem se desenvolvendo desde 1987 e inicia-se na FABICO². Quando, em meio às aulas (então de laboratório preto-e-branco), as luzes se apagavam, algo se revelou. Era algo da ordem do fascínio, do extraordinário, quase mágico: ser capaz de processar e ampliar aqueles pequenos negativos. Trazer à luz coisas que às vezes pareciam não estar lá ao olhar. Simular o movimento não captado pelo olho, capturar detalhes com uma lente, deixar muito grandes objetos muito pequenos.

Como escreveu Walter Benjamin: "A natureza que fala à câmara não é a mesma que fala ao olhar; é outra, especialmente porque substitui a um espaço trabalhado conscientemente pelo homem, um espaço que ele percorre inconscientemente." 3 Ao imaginarmos um homem caminhando, não conseguimos perceber

\footnotetext{
1 BRITES, 2002, p. 18.

${ }^{2}$ Faculdade de Biblioteconomia e Comunicação da UFRGS.

${ }^{3}$ BENJ AMIN, 1994, p. 94.
} 
a exata fração de segundo em que ele dá um passo. Graças aos seus recursos técnicos, tais como a velocidade baixa ou velocidade muito alta ou mesmo a ampliação, a fotografia revela muito mais do mundo do que é percebido conscientemente. Para Benjamin a diferença entre técnica e magia é uma variável totalmente histórica. Em Pequena História da Fotografia, a frase reproduzida aparece antes de discorrer sobre o trabalho de Karl Blossfeldt. No artigo o autor analisa certas espécies botânicas fotografadas com a forma de mastros totêmicos, permitindo entender que as imagens dos detalhes assépticos de ervas-daninhas nos falam de outras esferas do conhecimento, não só da botânica. O caráter mágico da fotografia é químico, é físico, é palpável, é comprovável; mas também é inconsciente, é imprevisível, é lembrança, é mistério, é sagrado.

Robert Hunt já escrevia em 1841 sobre o anúncio da descoberta (fotográfica, 1839) em que a luz, "[...] o mais sutil dos elementos, era um misterioso agente da visão [...]". ${ }^{4}$ Através dela permitia-se que a mais fugidia das sombras fosse permanentemente registrada, e possuísse, ao mesmo instante, muito do maravilhoso e do bonito.

Após anos de prática de laboratório pretoe-branco, captura de imagens analógicas em pequeno e grande formato e ensino de fotografia no ensino superior, iniciei em $2003^{5}$ uma pesquisa nos chamados Processos Fotográficos Históricos, Experimentais ou Alternativos. Recebem este nome os processos fotográficos praticados desde 1839 até o final do século XIX e início do século XX. Foram extintos dando lugar a outros mais simples, rápidos e vantajosos economicamente para a indústria fotográfica (liderada pela empresa Kodak).

Dentre os objetivos da pesquisa estavam fazer o resgate teórico e prático de técnicas desenvolvidas no século XIX - tanto em termos de captura de imagens quanto de processamento dos negativos e positivos - e propor uma alternativa em materiais contemporâneos. O problema inicial que se colocava era a articulação entre os processos fotográficos históricos e as novas tecnologias digitais (naquele momento câmeras digitais de pequeno formato). Os resultados da pesquisa deveriam

\footnotetext{
${ }^{4}$ HUNT, 1841, p. iii.

${ }^{5}$ Com o apoio da Pró-Reitoria de Pesquisa da ULBRA. O título de cadastro da pesquisa denominava-se $x x x$.
}

ser aplicados em sala de aula ${ }^{6}$.

Após a revisão de literatura foram escolhidas as técnicas da Cianotipia ${ }^{7}$ e do Anthotype ${ }^{8}$ ou Phytotype. Estas apresentavam fácil execução, necessitavam poucos materiais químicos e eram classificadas como menos tóxicas. ${ }^{9}$ Ao término da pesquisa, haviam sido satisfeitas as etapas da pesquisa acadêmica e obtidos resultados imediatamente incorporados à disciplina que ministrava naquela oportunidade.

Paralelamente desenvolvi uma série de impressões fotográficas que receberam o nome de Ilex Matetype ${ }^{10}$. O nome deve-se ao uso de erva-mate (Ilex Mate) na emulsão fotográfica.

Como decorrência, o meu projeto de doutorado $^{11}$ deu continuidade à pesquisa relatada nos parágrafos anteriores, e objetivava aprofundar os conhecimentos destes processos históricos e se focar naqueles conhecidos como Primitivos ou Early Photographic Processes. Devido ao caráter prático da ênfase em Poéticas Visuais, o resultado da tese são séries fotográficas que vêm sendo desenvolvidas desde 2005. Tecnicamente descrito foram em-

\footnotetext{
${ }^{6}$ De 2003 a 2004 leciono a disciplina xxx. Na disciplina percorre-se a trajetória da história da fotografia e sua relação com a arte desde o século XIX até o presente. São propostos exercícios práticos durante o semestre, que incluíam a cianotipia, a partir desta pesquisa. E é uma das práticas vistas pela Oficina de Fotografia Experimental, do mesmo curso desde 2007. A cianotipia também foi utilizada durante a disciplina de $x x x$.

7 O Cianótipo, Cianotipia (Cianotype) é um processo fotográfico conhecido também como Blueprint, pois baseado na sensibilidade dos sais de ferro aos raios U.V., por isso é classificado também como iron printing (FARBER, 1998). Desenvolvido por Sir John Hershel em 1842, é um dos primeiros processos fotográficos permanentes e um dos mais antigos.

8 O nome origina-se da palavra grega Antho, que significa flor; pois na base deste tipo de emulsão poderiam ser empregadas pétalas de flores, pigmentos de plantas ou frutas silvestres. O processo do Phytotype é descrito por Sir John Frederick William Herschel (1792-1871) no artigo On the Action of the Rays of the Solar Spectrum on Vegetable Colours, and on some new Photographic Processes lido em 26 de junho de 1842 para a Royal Society em Londres, GrãBretanha.

${ }^{9}$ Boa parte dos produtos químicos empregados nos processos do século XIX são cancerígenos, podem causar reações devido aos vapores tóxicos, manchas, corrosões na pele, entre outras patologias.

10 Composta por três séries (Jardim Secreto, Shadows, Old Times) foram selecionadas para uma exposição individual em Porto Alegre, na Galeria Lunara, Centro Cultural Usina do Gasômetro, 2004. Mais tarde, ainda no mesmo ano, a série Shadows participou da exposição de seleção do Prêmio Porto Seguro de Fotografias em São Paulo na categoria Pesquisas Contemporâneas.

11 Inicio no Programa de Pós-Graduação em Artes visuais,
} ênfase em Poéticas Visuais, UFRGS em 2005. 
pregadas a daguerreotipia ${ }^{12}$, o papel salgado ${ }^{13}$, os processos do colódio úmido (ambrótipos ${ }^{14}$ e tintypes) ${ }^{15}$, a goma bicromatada ${ }^{16}$ e o Kallitype ou Marrom Vandyck ${ }^{17}$. Há também uma parte escrita da tese onde devem ser aprofundadas questões conceituais, tais como as referências da historiografia da arte e da iconologia e descrita a metodologia empregada, levando em consideração o processo de trabaIho artístico. Neste artigo pretendo trazer duas questões conceituais decorrentes do trabalho prático que denominei de práticas híbridas e alquimia.

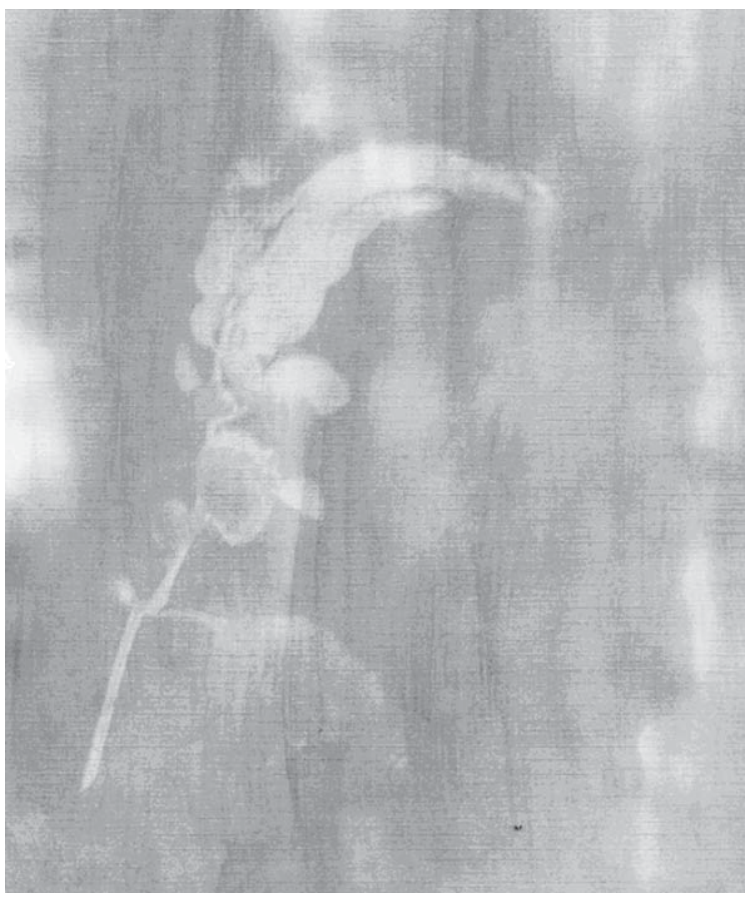

FOTOGRAFIA 1 - Série J ardim Secreto \#2, Ilex Matetype, 21 $\times 17 \mathrm{~cm}, 2004$.

\section{Práticas Híbridas}

A Camera Obscura ${ }^{18}$ que daria origem à câmera fotográfica como ainda hoje a conhecemos, e a observação de que certas substâncias mudam de cor ao entrar em contato com a luz, vão ser o ponto de partida para pesquisadores do início do século XIX, para experimentar, testar e desenvolver emulsões fotográficas com materiais químicos os mais diversos - tanto para o suporte positivo/negativo, como para as cópias positivas.

É em 1833 que ocorre a William Henry Fox Talbot, ao fazer desenhos com a ajuda de uma câmera lúcida ${ }^{19}$, a possibilidade de fixar para sempre as imagens com produtos químicos. ${ }^{20}$ Talbot apresenta o artigo Some account of the Art of Photogenic Drawing, or the Process which Natural Objects may be made to delineate themselves without the aid of the Artist's Pencil ( 31 de Janeiro de 183921) onde descreve seus experimentos e o processo decorrente: o Calotype $^{22}$ (em grego significa kalos, bonito). Mais tarde, porém, preocupado com os direitos autorais do mesmo, passa a designá-lo Talbotype.

O Calotype ou Talbotype é um negativo/positivo de papel emulsionado com produtos fotossensíveis. O negativo de papel incorpora as texturas do mesmo, originando uma imagem positiva borrosa, granulada e, conforme absorve as características do papel que o originou, possibilita intervenções criativas e corretivas. Por estas características formais venho trabaIhando com negativos em papel desde 2005.

Os materiais empregados por Talbot em suas primeiras tentativas de fixar a imagem fotográfica eram o pincel para o emulsionamento dos papéis (que é um material da pintura); o papel de desenho (como suporte da imagem fotográfica) e a camera obscura/lúcida, utilizadas como recurso auxiliar do desenho. As práticas manuais e o emprego de materiais de outras áreas foram vistos nos processos primitivos. Estes recursos também

\footnotetext{
${ }^{18}$ Caixa, quarto, ou qualquer local escuro no qual é feito um pequeno furo, que permita a passagem da luz do dia, penetrando na escuridão desta câmara. A imagem aparece na parede oposta de cabeça para baixo e revertida lateralmente.

19 Aparato ótico que permitia a visualização de uma cena e a conseqüente cópia da mesma através de desenho, por exemplo

20 WEAVER, 1992, p. 76.

21 TALBOT, 1800-1843, p. 120-121.
} 
eram empregados no Papel Salgado, Chrysotype ${ }^{23}$, Cianótipo, Phytotype, Amphitype ${ }^{24}, \mathrm{Al}-$ bumen paper ${ }^{25}$, Goma Bicromatada, Platinum ${ }^{26}$ e o Palladium ${ }^{27}$, praticados largamente pelos movimentos artísticos Pictorialismo (Europa) e o Photo-Secession (EUA).

O Movimento Pictorialista foi uma reação à industrialização da fotografia, uma oposição à valorização exclusivamente técnica, afastada de seu sentido estético. "Afirmando o caráter artístico da fotografia, o movimento pictorialista define a imagem fotográfica como o resultado da interpretação do sujeito-fotógrafo, que atua como um intermediário entre o tema/ objeto e o médium."28 Buscava modificar o caráter documental que se estabelecera na Europa durante a segunda metade do século XIX, já que a fotografia na Europa foi orientada por noções do pitoresco (ou seja, pobres, estrangeiros), do importante (ou seja, ricos e famosos) e do belo. ${ }^{29}$

As primeiras manifestações do movimento ocorreram em Viena, Londres e Paris a partir de 1890. Henry Peach Robison advogava que a fotografia deveria ser um híbrido entre o fato e o artifício. Suas manipulações deliberadas eram significativamente controvertidas para a comunidade artística e fotográfica. Para elas a fotografia deveria ser um registro imediato do mundo visível. ${ }^{30}$

No início dos anos de 1900, o movimento Photo-Secession liderado por Alfred Stieglietz e Edward Steichen publicava a revista Camera Work, considerada o começo da fotografia moderna. O movimento declarava a fotografia artística não constrangida pelo realismo documentário. Para declarar esta independência os membros do movimento adotaram uma estética fotográfica feita à mão e não necessaria-

\footnotetext{
22 WARE, 1994.

23 Processo positivo-negativo, aplicado sobre papel. Material fotossensível: sais de ouro.

24 Positivo ou negativo sobre papel. Material fotossensível: sais de mercúrio.

${ }^{25}$ Processo positivo-negativo, aplicado sobre papel. Material fotossensível: Nitrato de Prata e Albumina.

${ }^{26}$ William Willis (1873). Processo positivo sobre papel. Material fotossensível: Platina.

${ }^{27}$ Processo positivo sobre papel. Material fotossensível: Paládio.

${ }_{28}$ MELLO, 1998, p. 14.

29 SONTAG, 2004, p. 78.

${ }^{30}$ COLEMAN, 2005.
}

mente reproduzível. ${ }^{31}$

Dominique Baqué 32 denomina de Neopictorialismo o interesse atual de artistas por estas técnicas antigas. Para o autor há um retorno da história, um pictorialismo contemporâneo. Este novo pictorialismo pretende perpetuar as mesmas práticas de seu homólogo do final do século XIX, em que se valorizava o gesto da arte e se exaltava a subjetividade criadora. Em seu ponto de vista hoje há uma integração às artes plásticas e não se reivindica mais a inclusão neste campo. Também não pretende-se com este movimento se opor às outras práticas fotográficas do momento: entende-se a pluralidade do campo.

É uma postura contemporânea a prática artística que engloba vários meios (fotografia e vídeo, por exemplo), o que pode ser denominado de prática híbrida. Segundo Dominque Berthet a hibridação (híbrido; cruzado; misturado) depois do século XIX é empregado “[...] para qualificar aquilo que é composto de dois elementos de naturezas diferentes de dois ou mais conjuntos [...]"33. Híbrido também significa “[...] que provém de duas espécies diferentes; e hoje, em biologia, 'de duas espécies ou variedades diferentes' [...]"34 Este conceito define nossa época, caracterizada por um questionamento dos limites, de uma recusa radical da especificidade e da pureza das artes. Ao voltarmos a analisar os processos primitivos fotográficos em seu tempo percebemos que esse questionamento não chegou a colocar-se.

As práticas híbridas contemporâneas estão em oposição direta às modernistas, ditadas pelo purismo do crítico Clement Greenberg. Segundo o autor: “El ámbito propio y único de cada arte coincide con todo aquello que es único en la naturaleza de su medio." 35 Para ele, a purificação de cada meio artístico era possível graças à eliminação dos instrumentos e efeitos tomados de empréstimo de outras áreas. Se, no entanto, a fotografia "nasce" da prática impregnada por outros meios, como reinvindicar um purismo técnico?

Como diz Marnin Young: "A fotografia é uma forma híbrida presa inevitavelmente entre o

\footnotetext{
${ }^{31}$ REXER, 2002, p. 13-14

32 2003, p. 147-148.

33 BERTHET, 1999, p. 32.

34 I bid., loc. cit.

35 BAQUÉ, 2003, p. 191
} 
passado e o futuro."36

Ao se renunciar às separações, para pensar na obra como uma mestiçagem de práticas e de materiais, há uma “[...] conjugação feliz entre a matéria e a forma, reconciliação entre a técnica e a arte." 37

\section{Alquimia}

Com o uso dos processos experimentais há uma valorização dos materiais usados, que podem acarretar grão e carne na superfície da fotografia, diferentemente dos papéis lisos e plásticos da modernidade. O uso do pincel ou de uma brocha, a aplicação de tintas aos trabalhos, ou o emulsionamento de outras superfícies como a tela e os tecidos, e a combinação de múltiplas exposições, ou múltiplos negativos são algumas das possibilidades que se abrem ao artista.

Katy Barron e Anna Douglas ${ }^{38}$ usam a expressão alquimia para traduzir o desejo de alguns fotógrafos/artistas (e eu me incluo entre eles) em explorar a percepção, particularmente conectada às noções de espaço, tempo, luz, reações químicas, o trabalho da matéria e as transformações das substâncias.

Através destas explorações alquímicas e as condições materiais das obras, o papel do artista e a natureza de sua atividade vão se modificar. Ele estará mais preocupado com o processo, os materiais e as experimentações. Transformar a banalidade cotidiana em imagens significativas de luz. Em sua origem fiIosófica a alquimia também pretendia que as transformações materiais fossem símbolos da transformação espiritual. ${ }^{39}$

Dentre os resultados obtidos com o uso destes processos ao longo das pesquisas empreendidas, encontram-se manchas provocadas por excesso de emulsão química ou descolorações decorrentes de uma lavagem forte demais; levantamentos e perdas de emulsão em certas partes do trabalho, quando aplicado ao vidro ou acrílico; riscos, marcas de digitais, craquelados; aderência de elementos externos à chapa ainda na secagem; a formação

\footnotetext{
${ }^{36}$ Os comentários dizem respeito à exposição The Image Wrought: historical photographic approaches in the Digital Age, no Harry Ramson Center Galleries, Universidade do Texas.

37 BAQUÉ, op. Cit., p. 148.

${ }^{38}$ BARRON, 2006, p. 8.

39 Ibid., p. 31
}

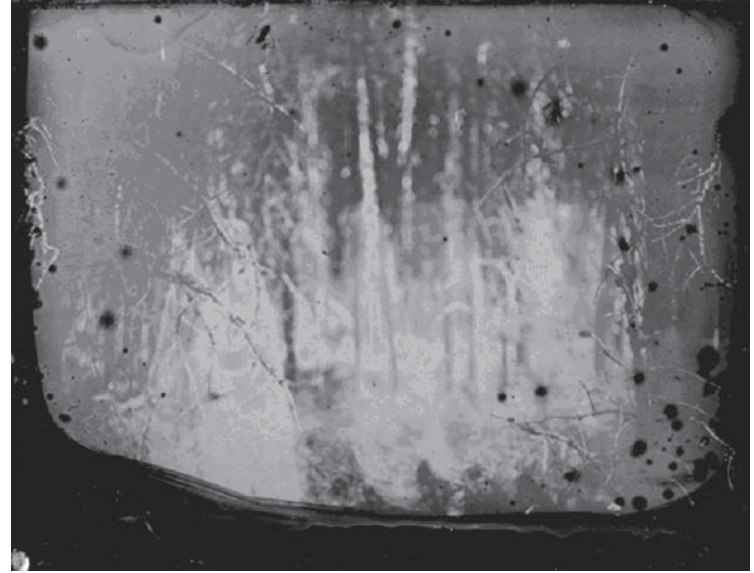

FOTOGRAFIA 2 - Série Fantasma, daguerreótipo, $4 \frac{1}{2} \times 5$ $1 / 2$ polegadas, 2006. Chapa de daguerreótipo sensibilizada, exposta e apagada para permitir novo processamento.

do oyster (mancha na borda dos tintypes pela química do nitrato de prata, com tonalidade madrepérola); o papel pode encolher e sofrer ondulações. Estas possibilidades de erro ou interferência no processo, obra do acaso ou serenpicidade aproximam-se de uma estética da imperfeição ou "[...] the imperfect work of man - and not much-diminished perfect work of God [...]. ${ }^{40}$

As emulsões, o papel em que seriam reproduzidas as fotografia, os químicos reveladores, fixadores, lavagens e secagens vão determinar o resultado final nestas fotografias, auxiliado pelo acaso. Dentro do percurso que a obra artística virá a experimentar ao longo de sua criação, podemos dizer que o acaso é um elemento importante: tanto inesperado como construído. Erros também podem trazer novos elementos a serem explorados. "E a relação do acaso e do desígnio mostram-se como a dialética do movimento criador. A criação continua direcionada por um projeto, porém inserido na continuidade de um processo."41

Durante o processo, tal qual a vida, em sua duração, podemos nos afetar pelos acontecimentos. Danos, aparecimentos e desaparecimentos, sonhos e pesadelos. Alguns serão maravilhosamente felizes, suaves e gentis; outros, absolutamente trágicos. Tais quais nossas experiências e vivências, que vão formar as várias camadas de nossa história, as vivências do processo aderem também à cópia final.

\footnotetext{
${ }^{40} \mathrm{HILL}$ apud NORDSTRÖM, 2008, p. 34.

${ }^{41}$ SALLES, 1998, p. 62-63.
} 


\section{Referências}

BAQUÉ, Dominique. La Fotografia Plástica. Barcelona: Gustavo Gili, 2003.

BARRON, Katy; DOUGLAS, Anna. Alchemy: twelve contemporary artists exploring the essence of photography. Londres: Purdy Hicks, 2006.

BATCHEN, Geoffrey. Each Wild I dea: writing, photography, history. Massachussetts: The MIT Press, 2002.

BENJ AMIN, Walter. Magia e Técnica, Arte e Política: ensaios sobre literatura e história da cultura. 7. ed. São Paulo: Brasiliense, 1994. (Obras Escolhidas, v. 1)

BERTHET, Dominique. Réflexions sur une esthétique de l'interaction. Recherches en Esthétique, Martinique, n. 5, p. 29-34, oct. 1999.

BRITES, Blanca; TESSLER, Elida (Org.). O Meio Como Ponto Zero: metodologia da pesquisa em Artes Plásticas. Porto Alegre: Ed. da Universidade, 2002. (Col. Visualidade, v. 4)

BURKHOLDER, Dan. Making Digital Negatives for Contact Printing. Carrollton: Bladed Iris Press, 1999

COLEMAN, David Lawrence. Pleasant Fictions: Henry Peach Robinson's composition photography. 2005. Doctoral dissertation - Faculty of the Graduate School, University of Texas, 2005, Austin, USA. Disponível em: <http : / / hdl .handle .net /2152 /2404> Acesso em: 04 jan. 2007.

FABER, Richard. Historic Photographic Processes. Nova Iorque: Allworth Press, 1998.

HERSCHEL, J ohn F.W. On the Action of the Rays of the Solar Spectrum on Vegetable Colours, and on some new Photographic Processes. Philosophical Transactions of the Royal Society of London, London, $v$. 132, p. 181- 214, jan. 1842.

HUNT, Robert. A Popular Treatise on the Art of Photography: including daguerréotype and all new methods of producing pictures by the chemical agency of light. Glasgow: Richard Griffin, 1841.

HUNT, Robert. A Manual of Photography. Londres: John Joseph Griffin, 1853.

MELLO, Maria Teresa Bandeira de. Arte e Fotografia: o movimento pictorialista no Brasil. Rio de Janeiro: Funarte, 1998. (Col. Luz e Reflexão).

NORDSTRÖM, Alison (Curadora). Truth Beauty: pictorialism and the photograph as art: 1845-1945. Vancouver: Vancouver Art Gallery, 2008.

REXER, Lyle. Photography's Antiquarian Avant-Garde: the new wave in old process. Nova Iorque: Harry N. Abrams, 2002.

SALLES, Cecília Almeida. Gesto I nacabado: processo de criação artística. 2. ed. São Paulo: Annablume/ FAPESP, 1998.

SONTAG, Susan. Sobre Fotografia. São Paulo: Companhia das Letras, 2004.

TALBOT, William Henry Fox. Some account of the Art of Photogenic Drawing: or the process which natural objects may be made to delineate themselves without the aid of the artist's pencil. London: Royal Society of London, 1839

WARE, Mike. Mechanisms of image deterioration in early photographs: the sensitivity to light of W.H.F. Talbot's halide-fixes images 1834-1844. Londres: Science Museum and National Museum of Photography, Film \& Television, 1994

WEAVER, Mike. Henry Fox Talbot: selected texts and bibliography. Oxford: Clio Press, 1992.

YOUNG, Marnin. The past is the new future. Afterimage, Austin, may 2006. Disponível em: <http://www. findarticles.com/p/articles/mi_m2479/is_6_33/ai_n16701832> Acesso em: 27 dez. 2006.

Recebido em julho de 2008

Aceito para publicação em setembro de 2008 